\title{
LIBERTAD E IGUALDAD EN EL PENSAMIENTO POLÍTICO DE NORBERTO BOBBIO: ¿SE PUEDE SER LIBERAL Y A LA VEZ SOCIALISTA?*
}

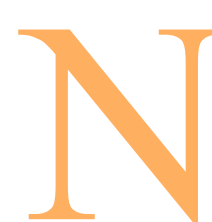

orberto Bobbio es un jurista y filósofo italiano que nació en el Piamonte, en 1909, y que vive actualmente en Turín, en el número 68 de la Via Sacchi, una calle que ahora cruza únicamente si va del brazo de Valeria, su mujer y compañera de toda la vida. Bobbio es ya un viejo y vive entonces instalado en lo que él mismo llamó «el crepúsculo que anuncia la noche». Precisamente, uno de sus últimos libros, titulado «De senectute», trata de la vejez y de la muerte, aunque no para glorificar la primera ni trivializar la segunda, como está hoy de moda entre algunos vendedores de ilusiones que tratan de presentar la vejez como el mejor de los mundos y a la muerte como un simple paso hacia nuevas formas de vida. Todo lo contrario, Bobbio considera que la vejez es el tiempo de la melancolía, o sea, el momento en que se toma mayor «conciencia de lo insatisfecho, de lo incompleto», aunque se trata también de un período de la vida en que podemos advertir mejor que «hay bondad en la racionalidad» y en el que «los afectos cuentan también más que los conceptos».

Bobbio, después de criticar ácidamente la retórica que pretende pintar la vejez casi como un estado de plenitud, alude en «De senectute» a los distintos modos de vivir la vejez, entre los que sobresalen el de los viejos satisfechos y el de los viejos desesperados, y se pregunta entonces cómo ha vivido él su propia vejez. Y ésta es su respuesta: «Diré con una sola palabra que tengo una vejez melancólica, entendiendo melancolía como la conciencia de lo no alcanzado y de lo ya no alcanzable. Se le ajusta bien la imagen de la vida como un camino, en el cual la meta se desplaza siempre hacia delante, y cuando crees haberla alcanzado no era la que tu habías figurado como definitiva. La vejez se convierte entonces en el momento en el cual tienes

\footnotetext{
${ }^{*}$ Conferencia en el Instituto Cultural de Las Condes, Santiago, 24 de septiembre de 1998.
} 
plena conciencia de que no sólo no has recorrido el camino, sino que ya no te queda tiempo para recorrerlo, y debes renunciar a alcanzar la última etapa. La melancolía está atemperada, no obstante, por la constancia de los afectos que el tiempo no consumió»».

Es difícil presentar a Bobbio ante un auditorio, porque en su actividad intelectual él no trabajó nunca en línea recta, sino en varias líneas a la vez, a saber, la filosofía general, la filosofía del derecho, la teoría política y los debates públicos más circunstancíales sobre temas que van desde el futuro de la democracia en Europa y la fundamentación de los derechos humanos, hasta la despenalización del aborto o la guerra aliada contra Irak.

«Me he ocupado de muchas cosas, quizás de demasiadas» confidenció cierta vez el propio Bobbio, y añadió todavía esto: «He recorrido varios caminos, pero, para ser franco, no he llegado al término de ninguno de ellos». Por lo mismo, la base del trabajo de Bobbio no ha sido el libro -aunque es autor de varios-, sino el artículo, incluso el artículo periodístico. En esos artículos, que él ha escrito por centenares y que tienen un carácter más crítico que sistemático, más cerca de las preguntas que de las respuestas, «el punto de partida de Bobbio -como apunta Alfonso Ruiz Miguel- suele ser un problema, cuyos términos desmenuza, para proponer al final una solución normalmente deductiva de la crítica de otras posiciones teóricas».

Quisiera pedirles que retuviéranos esa última frase -«para proponer al final una solución normalmente deductiva de la crítica de otras posiciones teóricas»-, porque es lo que acontece también cuando Bobbio plantea el problema de la libertad y de la igualdad en las sociedades democráticas contemporáneas. Adelantándome a las conclusiones que ofreceremos en la parte final de esta conferencia, Bobbio asume que la libertad es el valor central del liberalismo, en tanto que la igualdad lo es del socialismo, y, acto seguido, sobre la base de la crítica de las versiones extremas tanto del liberalismo como del socialismo, propone al fin la difícil solución de conciliar uno y otro valor, esto es, de ajustar las exigencias de la libertad de la gente con las aspiraciones de ésta por sociedades más igualitarias, todo lo cual le lleva a acercar posiciones entre liberales y socialistas y a declararse incluso, él mismo, un liberal socialista, o sea, alguien que cree tanto en el valor de la libertad como en el de la igualdad, y que, por lo tanto, rechaza, por una parte, el postulado de que la libertad tenga que ser conseguida al precio de sacrificar la igualdad, y, por la otra, el de que para tener igualdad tengamos que inmolar la libertad de las personas.

Pero volvamos a nuestra afirmación de hace un instante en el sentido de que Bobbio ha trabajado de hecho en varias líneas o campos a la vez. En atención a eso, uno podría decir que hay por lo menos cuatro Bobbios: el Bobbio filósofo, el Bobbio jurista o filósofo del derecho, el Bobbio teórico 
de la política y el Bobbio como figura más ampliamente intelectual que habla y escribe, ya no como especialista, sobre determinados asuntos que interesan de preferencia a sus contemporáneos. En la manera cómo Bobbio se desenvuelve en todos estos campos, habría que destacar algo que él proclamó alguna vez: «He aprendido a respetar las ideas ajenas, a detenerme en el secreto de cada conciencia, a entender antes de discutir y a discutir antes de condenar».

Pero en esos posibles cuatro Bobbios hay cuando menos otra constante, a saber, el carácter analítico que acompaña el modo de pensamiento del autor y su consiguiente estilo de expresión.

Analítico, porque Bobbio muestra una disposición intelectual antes a reconocer problemas que a resolverlos, en el entendido de que solo un problema bien planteado tiene reales posibilidades de ser luego resuelto de algún modo.

Analítico, porque tiene también una disposición para tratar los problemas dentro de los límites de lo razonable, esto es, con la aceptación de las posibilidades pero también de los límites de la razón humana, resignándose, como Wittgenstein, a hablar de lo que sabemos y a callar acerca de lo que ignoramos o no podemos saber.

Analítico, además, por una cierta consideración que Bobbio hace de sí mismo como empirista, o sea, como alguien que ha tratado siempre de buscar los hechos, de razonar a partir de ellos y de mantener separados los juicios de hecho de los juicios de valor, porque, en expresiones del propio Bobbio, «lo opuesto de una investigación a-valorativa es una investigación tendenciosa. Aléjense de la ética de la a-valoración, que es la ética del científico, y acabarán pronto en la propaganda».

Analítico porque Bobbio reconoce también una propensión antes a comprender el mundo que a transformarlo, invirtiendo así el aforismo de que los filósofos sólo han hecho explicar el mundo y de que ya es hora de cambiarlo.

Analítico también porque Bobbio muestra siempre una abierta disposición a aclarar el sentido de los términos con que trabajamos habitualmente a propósito de los distintos problemas, por entender ahora que todo lenguaje es siempre ambiguo y que filosofar podría equivaler, como creía Ortega, a una inmersión en el pequeño abismo que es cada palabra.

Analítico por ser portador, asimismo, de un cierto sentido de la complejidad de las cosas y por admitir que la prueba de una inteligencia superior -como decía Scott Fitzgeraldpodría consistir en la posibilidad de mantener en la cabeza dos ideas opuestas a la vez sin perder por ello la capacidad de funcionar. 
Analítico, en fin, por la percepción, declarada por el propio Bobbio, de que la «filosofía analítica constituye una escuela de racionalidad, un ejercicio de paciencia, una educación en la seriedad y una invitación a la claridad y al rigor». «Fiel al método analítico -agrega todavía Bobbio-, me preocupo de observar un problema desde distintos enfoques, termino por no conseguir una definición lineal y por dejar abierta la cuestión».

Siempre como parte de esta presentación que venimos haciendo de Bobbio, digamos por último que tuvimos la suerte de tenerlo aquí, en Santiago y en Valparaíso, hacia fines del año 1986, una época en la que, de lado y lado, vivíamos una situación política interna marcada por el pesimismo: por una parte, el pesimismo de quienes pensaban que la democracia tendría que esperar muchos años más, y, por la otra, el pesimismo de quienes veían venir la democracia, según el itinerario trazado por la Constitución de 1980, y, con ella, el caos económico y social.

En la conferencia que ofreció ese año en Valparaíso, Bobbio sostuvo que la democracia era un proceso irreversible, no sólo en América Latina, sino también en los países del este de Europa, porque, según dijo, «la historia humana tiende hacia la libertad».

Al expresarse de ese modo, Bobbio ligó democracia con libertad, lo cual quiere decir, como es bien patente para todos, que la democracia es la forma de gobierno que de mejor manera consagra, protege y promueve la libertad de las personas en todas sus diferentes modalidades o expresiones. ¿Pero qué pasa con la igualdad, en concreto con la igualdad material, esto es, con la igualdad en las condiciones de vida de las personas? ¿Es la democracia una forma de gobierno adecuada para conseguir no sólo sociedades más libres, sino también más igualitarias?

Tales preguntas nos ponen ya en el tema mismo de esta conferencia, aunque antes de desarrollarlo me gustaría dejar precisada una cosa.

Cuando Bobbio entraba en la Facultad de Derecho de la Universidad de Valparaíso para dar su conferencia de 1986, unos estudiantes desplegaron un lienzo con la siguiente frase: «Bienvenido profesor Bobbio: los que luchan por la democracia y la libertad lo saludan».

Bobbio insistió en fotografiarse junto a ese lienzo, y, más tarde, en el diario «La Stampa» de Torino, al mes siguiente de su visita a Chile, publicó un breve artículo alusivo a su viaje a nuestro país, que tituló «Aplausos a la libertad». Por cierto, la idea que Bobbio expuso en ese artículo fue la de que los aplausos que había escuchado en Valparaíso luego de su conferencia no iban dirigidos a su persona, sino que eran más bien la expresión de un sentimiento común, de una voluntad concorde y de una esperanza también compartida a favor de la libertad y de la democracia. Todo lo cual recuerda y actualiza, por último, el pensamiento de John Stuart Mill: «Una 
persona con una creencia representa una fuerza social equivalente a la de noventa y nueve personas que sólo se mueven por interés».

A propósito de Mill, un autor admirado por Bobbio, vale la pena recordar que suele ser filiado también como un autor liberal próximo al socialismo, porque siempre estuvo preocupado, según nos recuerda Perry Anderson en un ensayo sobre Bobbio, de «combinar la máxima libertad de acción individual» con «una participación igualitaria de todos los beneficios del trabajo colectivo».

Las propuestas de Bobbio acerca de la libertad y de la igualdad están estrechamente ligadas a la idea que el autor italiano tiene acerca de la democracia como forma de gobierno. Corresponde entonces que fijemos brevemente cuál es la definición que Bobbio propone de la democracia, a fin de detenernos luego en la cuestión central que nos interesa, a saber, cuánta libertad y cuánta igualdad puede proveer la democracia a las sociedades que optan por gobernarse democráticamente.

Bobbio, según sus propias palabras, adhiere a una definición mínima de democracia, lo cual es lo mismo que decir una definición procedimental o una definición formal de la misma.

Una definición semejante considera la democracia como un conjunto de reglas y procedimientos que permiten adoptar las decisiones colectivas o de gobierno, esto es, aquellas decisiones que, junto con interesar a todos los miembros de la sociedad, resultan además vinculantes para todos ellos.

«Todo grupo social -escribe Bobbio- tiene necesidad de tomar decisiones vinculantes para todos los miembros del grupo, a objeto de proveer a la propia supervivencia, ya en el interior, ya en el exterior».

Lo anterior quiere decir que en toda sociedad resulta necesaria la adopción de decisiones orientadas hacia otros, o hacia todos, y estas decisiones, que podemos llamar decisiones colectivas o de gobierno, al no poder ser tomadas por los individuos en forma aislada, es preciso que lo sean por alguien y que este alguien proceda conforme a determinadas reglas y procedimientos que se hallan preestablecidos.

En otras palabras: en sociedades extensas y complejas como las que nos toca vivir, que demandan constantemente medidas o decisiones de interés común, resulta inevitable plantearse la pregunta acerca de quién podrá tomar tales decisiones, o sea, quién estará a cargo del gobierno.

Toda forma de gobierno, en verdad, responde a esa pregunta. Las modalidades no democráticas contestan diciendo que las decisiones colectivas deben ser tomadas por una sola persona, o bien por un grupo limitado de personas, a quienes se suele identificar muchas veces como los llamados naturalmente a la tarea de gobierno: los más sabios, los más ricos, los que reconocen cierta filiación con el anterior gobemante, cierta clase social, una 
casta religiosa o profesional cualquiera. En cambio, la democracia admite que no hay un criterio cierto ni compartido acerca de quién deba gobernar y, por lo tanto, admite que el gobierno, esto es, la facultad de adoptar decisiones colectivas, quede en manos de cualquiera, sí, de cualquiera, aunque a condición de que haya obtenido para sí la mayoría en las elecciones que se celebren periódicamente con este fin.

Hay entonces en la democracia una curiosa combinación de cautela y osadía: cautela en cuanto ella carece de una respuesta fija y predeterminada a la pregunta de quién debe gobernar, y osadía porque se atreve a responder que puede gobernar cualquiera, sin otra condición que obtener para sí la mayoría.

Así las cosas, Bobbio pudo escribir que la democracia es una de las varias formas de gobierno que conocemos, concretamente «aquella en la que el poder se encuentra no en las manos de una sola persona o de pocas, sino de todas, o, mejor, de la mayor parte, y que, en cuanto tal, se contrapone a las formas autocráticas de gobierno, tales como la monarquía y la oligarquía». Por lo mismo, "democrático es un sistema de poderes en el que las decisiones colectivas, o sea, las decisiones que interesan a toda la colectividad (por pequeña o grande que sea) son tomadas por todos los miembros que la componen». En otras palabras, «la democracia es la contraposición del método de la discusión y la persuasión, por un lado, y el de la violencia, por otro. Es democrático aquel que trata de resolver una controversia no suprimiendo al adversario, sino convenciéndole, y si no logra convencerle, estableciendo un acuerdo basado en un compromiso. Cuando además los contendientes son muchos y el compromiso se hace difícil, vale la regla de la mayoría. Una regla puramente cuantitativa -concluye Bobbio-, pero siempre es mejor contar las cabezas que cortarlas».

«Contra la objeción de que la definición de la democracia procedimental, que concierne a la estructura jurídica del Estado democrático, es indiferente a los valores, es preciso insistir en la consideración de que el fin principal de estas reglas es posibilitar la solución de los conflictos sociales a través de la contratación entre las partes y, cuando la contratación no tiene éxito, a través del voto de mayoría, excluyendo el recurso a la violencia».

En suma: el principio básico de la democracia sería que en la adopción de las decisiones colectivas debe participar el mayor número de personas (toda la población adulta, por ejemplo); y establecido que el grupo social completo no puede instituir directamente, una a una, tales decisiones, ese mismo principio estipula que quienes adopten en el hecho las decisiones de gobierno deben ser representantes del grupo, lo cual sólo es posible si el grupo designa a sus representantes por medio de elecciones. 
En una democracia, entonces, el poder no es ejercido directamente por el pueblo, porque en sociedades como las que vivimos el pueblo no puede estar reunido permanentemente en asamblea para acordar todas las decisiones de interés común; pero sí puede decirse que en una democracia el poder proviene o deriva del pueblo, en el sentido de que es éste al que corresponde, por medio de determinaciones de mayoría, elegir a quienes tendrán a su cargo la tarea de tomar decisiones colectivas. A su vez, los elegidos para esta función, especialmente en el caso del órgano o poder legislativo, y una vez agotados los mecanismos de discusión y transacción que puedan conducir a la unanimidad o a consensos amplios, resolverán finalmente sobre el contenido de sus propias decisiones aplicando también la regla de la mayoría. Así, sólo en una democracia directa puede afirmarse que el pueblo decide o gobierna; en cambio, en nuestras democracias representativas, lo único que puede decirse es que el pueblo elige a quién decide o gobierna.

Establecido ya cuál es a grandes rasgos el concepto de democracia de Bobbio, ¿qué relación ve ahora el autor entre democracia y libertad?

Sin duda que «libertad» es una de aquellas que solemos llamar «grandes palabras» y que encontramos con frecuencia en las obras y discursos de filósofos, intelectuales y políticos, aunque se trata también de una palabra cuyo significado no resulta fácil precisar.

Alf Ross, un jurista escandinavo, contemporáneo de Bobbio, a quien debemos un notable libro acerca de la democracia -me refiero a «¿Por qué democracia?», de 1952-, decía de la libertad que «difícilmente haya otra palabra utilizada tan extravagantemente, tan ensalzada y loada, pero que al mismo tiempo sea tan carente de un significado claro y preciso. Ambas cosas, empero, van juntas, porque el significado es tan fluido, admite una explicación tan lata. "Libertad", concluía Ross, es una de esas palabras sonoras cargadas de sugestión, a las que se recurre más bien para despertar sentimientos en el ánimo que pensamientos en la cabeza».

Consciente también Bobbio de lo anterior, el autor italiano elude toda intromisión metafísica en la idea de libertad y se limita a constatar que ciertas libertades son indispensables para el ejercicio del poder democrático, puesto que, por una parte, sin esas libertades el principio o regla de la mayoría perdería todo sentido, y, por la otra, la democracia es también la forma de gobierno que ofrece mejores condiciones para la protección, subsistencia y desarrollo de esas mismas libertades. De este modo, las libertades de que habla Bobbio son necesarias para que pueda instalarse un poder verdaderamente democrático, a la vez que este poder reconoce un compromiso de protección y desarrollo de esas mismas libertades.

Sostiene Bobbio que el estado liberal, o sea, el Estado de las libertades, es el presupuesto no sólo histórico, sino también jurídico del Estado democrático, 
o sea, del Estado en el que el gobierno está en manos de la mayoría. «Estado liberal y Estado democrático -escribe el autor- son interdependientes de dos formas: en la dirección que va desde el liberalismo hasta la democracia, en el sentido de que se necesitan ciertas libertades para el ejercicio del poder democrático, y en la dirección opuesta, que va desde la democracia hasta el liberalismo, en el sentido de que se necesita el poder democrático para garantizar la existencia y persistencia de las libertades fundamentales».

Pues bien: entre esas libertades que junto con ser presupuestos de la democracia son salvaguardadas por esta forma de gobierno, están ciertamente la libertad de pensamiento, de expresión, de reunión, de empresa, de asociación. En el caso de esta última, ella dice relación preferente con el derecho de las personas a asociarse para fines políticos, o sea, con el derecho a constituir partidos políticos y a participar en ellos. A este mismo respecto, otro jurista de nuestro siglo que realizó también contribuciones de importancia a la teoría democrática -Hans Kelsen- dijo, con razón, que los partidos políticos constituyen «uno de los elementos más destacados de la democracia». «Es patente -agregó todavía Kelsen- que el individuo aislado carece por completo de existencia política positiva por no poder ejercer ninguna influencia efectiva en la formación de la voluntad común, y que, por consiguiente, la democracia sólo es posible cuando los individuos, a fin de lograr una actuación sobre la voluntad colectiva, se reúnen en organizaciones definidas por diversos fines políticos». «Sólo por ofuscación o dolo -concluyó Kelsen a este respecto- puede sostenerse la posibilidad de la democracia sin partidos políticos».

Porque la democracia se erige sobre un andamiaje de libertades, libertades con cuya subsistencia y desarrollo la democracia asume un explícito e ineludible compromiso, todo aquel que de valor a la libertad y considere a ésta, como dice Ross, «un bien personal y humano», tiene más que buenas razones para preferir la democracia como forma de gobierno.

¿Pero qué pasa con la igualdad? O, mejor aún, ¿cuál es el compromiso que la democracia asume con la igualdad?

Convengamos que «igualdad» es otra de esas «grandes palabras» que aparece también con frecuencia en las obras de filósofos, pensadores y políticos, lo mismo que pasa con la palabra «libertad», aunque se trata de un término que ofrece todavía mayores dificultades a la hora de su conceptualización.

Hay, desde luego, una igualdad jurídica básica, a saber, la de que todos somos sujetos de derecho, esto es, todos podemos tener derechos y obligaciones jurídicas, destacando entre los primeros los llamados derechos humanos, 
o derechos fundamentales, que adscriben a toda persona, sin distinción, por el solo hecho de ser tal.

Siempre en el plano jurídico, tenemos también la llamada «igualdad en la ley», en virtud de la cual decimos que las leyes no pueden establecer diferencias arbitrarias entre las personas, esto es, diferencias no justificadas racionalmente. Está también, por cierto, la «igualdad ante la ley», en mérito de la cual quienes ejecutan o aplican las leyes, esto es, el Poder Ejecutivo y el Poder Judicial, no pueden hacerlo estableciendo diferencias entre las personas que las propias leyes no hayan establecido previamente. En otras palabras: la igualdad en la ley es una demanda que se dirige al legislador y es éste, por tanto, el llamado a respetarla. Por su parte, la igualdad ante la ley es una exigencia que se plantea tanto al Ejecutivo como al Poder Judicial y son ahora estas autoridades las llamadas a observar escrupulosamente dicho principio.

Tenemos también la igualdad política, propia de toda democracia, en razón de la cual toda la población adulta puede participar en las elecciones y conforme a la cual el voto de todos cuenta por uno.

¿Pero qué ocurre con la igualdad en sentido material, esto es, con la igualdad en las condiciones de vida de las personas? Así como la democracia asume un compromiso bastante evidente con la libertad, según veíamos antes, ¿adopta ella un compromiso similar con la igualdad material, esto es, cabe esperar de la democracia que junto con garantizar una sociedad de libertades consiga también una sociedad que reduzca las desigualdades en las condiciones de vida de las personas?

La verdad es que si uno adhiere a una definición procedimental de democracia, como hace el propio Bobbio, tendría que coincidir en que quienes ejercen el poder democráticamente pueden trabajar tanto a favor como en contra de una mayor igualdad en las condiciones materiales de vida de la gente. Ello va a depender de quienes ganen las elecciones y del tipo de programa que ejecuten luego desde el gobierno. Por lo mismo, los partidarios de una mayor igualdad en las condiciones materiales de vida que prevalecen en la sociedad no tienen que declararse enemigos de la democracia por el hecho de que ésta no garantice por sí sola ese tipo de igualdad. Lo que tienen que hacer es competir en las elecciones para instalar en el poder a las personas, a los partidos o a las coaliciones de partidos que, de acuerdo a sus trayectorias políticas y a sus programas, ofrezcan mejores garantías de una sociedad más igualitaria.

Pero el punto central es éste: Bobbio cree posible que una democracia, junto con declarar y proteger las libertades de las personas, avance en pos de una sociedad más igualitaria desde el punto de vista de las condiciones materiales de vida, esto es, en pos de una sociedad donde no tengamos, por 
un lado, la vida demasiado dulce de unos pocos que viven en la abundancia, cuando no en la opulencia y en el derroche, y, por el otro, la existencia demasiado amarga de muchos que no tienen siquiera lo indispensable para satisfacer regularmente sus necesidades más básicas de alimentación, vivienda, vestuario, salud y educación.

Sin embargo, cuando Bobbio se muestra partidario de la igualdad en el sentido antes indicado, no está pensando en una igualdad absoluta, en una igualdad de todos en todo, en una igualdad regimentada e impuesta con la fuerza del Estado. En lo que está pensando es en una igualdad relativa, en una igualdad de todos en algo, en una igualdad en el sentido de que todos puedan satisfacer a lo menos sus necesidades básicas, para lo cual se precisa, es cierto, un papel activo de parte del Estado.

En idea de Bobbio, por lo mismo, se trata de conseguir no propiamente una sociedad de iguales, sino únicamente una sociedad más igualitaria, o menos desigualitaria, de las que hemos conseguido realizar hasta ahora; o sea, se trata de una sociedad en la que lo que se postula no es que nadie coma torta para que todos puedan comer pan, sino de una sociedad en la que a lo menos todos puedan comer pan, sin perjuicio de que algunos, o incluso muchos, en razón de su trabajo, de sus méritos, de su esfuerzo o de su suerte, puedan acceder también a las tortas y a otros manjares semejantes. La sociedad que describimos de esa manera, en consecuencia, tendría que ser mucho mejor que el tipo de sociedad satisfecha que algunos países, entre ellos el nuestro, han conseguido instalar en los cuatro o cinco mejores barrios de las cuatro o cinco mejores ciudades. Tendría que ser una sociedad distinta de la que se configura cuando unos pocos van cómodamente instalados en los camarotes de lujo de la nave, mientras los demás se las arreglan como pueden tendiendo mantas sobre la cubierta o en las bodegas, sin olvidar -por último- a los que nadan alrededor de la embarcación y tratan desesperadamente de subir a ella.

El liberalismo -sostiene Bobbio- «se inspiró sobre todo en el ideal de libertad, pero es inútil ocultamos que la libertad de iniciativa económica ha creado enormes desigualdades no sólo entre hombre y hombre, sino también entre Estado y Estado». Por su parte, el socialismo se inspiró sobre todo en el ideal de igualdad, aunque resulta inútil ocultarnos que creó también enormes restricciones a la libertad de las personas. En otras palabras: un liberalismo extremo sacrifica la igualdad en nombre de la libertad y enarbola el nombre sagrado de la segunda cada vez que alguien nombra la primera, mientras que un socialismo del tipo de los llamados «socialismos reales» inmola la libertad en nombre de la igualdad y levanta el estandarte de la segunda para justificar restricciones inaceptables a la primera. Esto significa, según el primero de esos puntos de vista, que si queremos libertad no queda 
más remedio que conseguirlo al precio de la igualdad, al paso que el segundo de tales puntos de vista nos dice que si querernos igualdad tenemos que pagar por ella el precio de la libertad.

Bobbio reacciona contra semejantes planteamientos $\mathrm{y}$, sin dejar de ser consciente de las fricciones que de hecho se producen entre libertad e igualdad, propicia un ideal que nazca de la exigencia de que los hombres, además de libres, sean iguales, aunque no iguales, claro está, en el sentido absoluto e irreal de este término.

Dicho de otra manera: Bobbio considera pertinente y posible demandar de la democracia un compromiso, a la vez que con la libertad, con una mayor igualdad en las condiciones materiales de vida de la gente, o sea, le parece adecuado pedir a la democracia no sólo la preservación y el desarrollo del régimen de libertades que la hacen posible, sino también una cierta voluntad igualitaria en el sentido de utilizar el poder del Estado para contribuir a morigerar las desigualdades materiales más manifiestas e injustas, así no más sea porque la presencia en una sociedad cualquiera de tal tipo de desigualdades puede tornar enteramente ilusorio y vacío, para quienes las padecen, el disfrute y ejercicio de las propias libertades.

Como dice Laski, citado por Alf Ross, «aquellos que viven en condiciones desiguales (económicas, sociales, culturales) no piensan en forma igual, y, por ende, el sentido común de los valores y la voluntad de comprensión recíprocas, que son requisitos previos de la democracia, pueden quebrarse si las condiciones llegan a ser excesivamente desiguales. Una comunidad con desigualdad vive siempre temiendo divisiones intestinas. $\mathrm{La}$ gente de una comunidad sólo tendrá un interés similar en la libertad cuando, para decirlo con términos imprecisos, tenga un interés similar en sus resultados. La libertad, pues, y a la larga, no podrá subsistir sin igualdad».

Según esa idea, por consiguiente, la igualdad no sólo no es un ideal incompatible con la libertad, sino, todo lo contrario, una cierta igualdad material mínima sería una condición para el ejercicio efectivo de la libertad y para la real consolidación de un régimen democrático. Puesto que, ¿cuál puede ser el real interés de una persona en sus libertades de pensar, de expresarse, de reunirse, de emprender, de asociarse, si es que sus condiciones materiales de vida la sitúan irremediablemente por debajo de la línea de pobreza o en un estado de franca indigencia?

En ello consiste la síntesis liberal-socialista propiciada por Bobbio y ahora puede entenderse posiblemente mejor esa parte del título de esta conferencia que alude a si se puede ser liberal y a la vez socialista.

Si por liberalismo, en sentido amplio, se entiende la doctrina que sostiene que los derechos de libertad son condiciones necesarias de toda auténtica democracia, y si por socialismo se entiende una doctrina que propicia 
un papel activo del Estado para conseguir una sociedad más igualitaria, aunque sin perjudicar el régimen de libertades, entonces Bobbio no tiene dificultad en calificar su posición de «liberalsocialismo» y en declararse él mismo un «liberal socialista».

Pero la propuesta de Bobbio no es simple ni fácil, porque todos sabemos que el liberalismo propicia menos Estado y el socialismo más Estado, de donde se sigue una evidente dificultad para conciliar ambas doctrinas. Sin embargo, un liberalismo con responsabilidad social no debería extremar su postulado a favor de menos Estado, mientras un socialismo liberador debería entender que no debe llevar hasta el extremo su postulado a favor de más Estado.

El propio Bobbio es el primero en reconocer que «el liberalsocialismo es sólo una fórmula», aunque también «indica una dirección», y esa dirección no es otra que la de mirar también la historia desde el punto de vista de los oprimidos.

Es cierto que se trata también de una fórmula política hibrida, quizás paradojal, pero ya advertía Rousseau que es siempre preferible ser hombres de paradojas que hombres de prejuicios. Se trata también, como alguien ha dicho, de «una fórmula química inestable», porque supone un equilibrio que no es fácil de conseguir ni de mantener. En la tensión libertad-igualdad, las basas pueden inclinarse exageradamente a favor de la primera, y entonces no tendremos más que un capitalismo agresivo que no conoce más ley que el mercado y que reduce todo a la condición de mercancía. Por otra parte, en dicha tensión entre libertad e igualdad las basas pueden inclinarse indebidamente a favor de la segunda, caso en el cual está ya probado que no conseguiremos otra cosa que un dirigismo estatal que asfixia la libertad e impone un igualitarismo empobrecedor.

Algo parecido ocurre también con la tensión que en toda sociedad democrática se produce entre orden y libertad. Es efectivo que en cierta medida orden y libertad se repelen, pero nadie aceptaría sensatamente hoy la idea de que para tener orden sea preciso sacrificar la libertad, como tampoco resulta razonable la idea de que todo orden deba ser rechazado en nombre de la libertad.

Precisamente, el desafío a este respecto consiste en armonizar orden con libertad, en advertir que hay una buena dosis de irresponsabilidad política, y hasta de inexcusable simpleza, tanto en la doctrina de quienes desearían sacrificar cándidamente el orden a la libertad, cuanto en la de quienes, presas fáciles del terror a la desintegración social y a la falta de autoridad y de dirección, propugnan el sacrificio inverso, esto es, sofocar al máximo las libertades para conseguir así un mínimo de orden. 
Nos preguntamos entonces si acaso la relación libertad-igualdad no debería ser planteada de la misma manera, sobre todo si por igualdad se entiende no la supresión de toda diferencia, sino, al modo de Bobbio, tan sólo la aproximación gradual, pero sostenida, a una «sociedad más igualitaria de las que hemos conocido y conseguido realizar hasta ahora». Por lo tanto, a lo que nos adherimos, según veremos más adelante, no es a la ideología de lo que podríamos llamar el «igualitarismo», o sea, la igualdad de todos en todo, sino, menos que eso, a la ideología de la igualdad, esto es, a la igualdad de todos en algo... De este modo, se trata de obtener una mayor igualdad y no una igualdad absoluta, en el sentido de propender, con medidas deliberadas y eficaces, pero que a la vez no mutilen el régimen de libertades, a una atenuación de «las diferencias de poder que existen entre los hombres».

En otras palabras, si en el transcurso de la revolución francesa, como dijo Lord Acton, «la pasión por la igualdad hizo vana la esperanza de la libertad», en el devenir de lo que hoy se llama la «revolución neoliberal» habría que postular que las aspiraciones por mayor libertad no caduquen los deseos también legítimos por una sociedad más igualitaria. Esto significa que la desigualdad material no tendría ya que ser vista como la sombra negra que proyecta inevitablemente el reinado de la libertad, sino como una imperfección de la propia libertad».

Por lo mismo, y pese a su indesmentible resonancia utópica, quizás no esté del todo desacertado el viejo lema revolucionario que pedía libertad, igualdad y fraternidad. Tal vez la fraternidad, esto es, la unión y buena correspondencia entre los que son o a lo menos se tratan como hermanos, pueda constituir el puente que se necesita tender entre los valores de la libertad y de la igualdad, a fin de que, reconociéndose distintos, no se repelan y propendan en cambio, junto con preservar sus respectivas autonomías, a ceder cada cual de sí en la proporción justa que permita la realización simultánea del otro.

«Nunca dejará de haber pobres en la tierra», admite uno de los libros del Antiguo Testamento. Sin embargo, lo que se concluye en ese mismo texto no es que debamos endurecer el corazón ante los más necesitados, sino todo lo contrario. «Por eso -sigue diciendo ese libro sagrado- te doy este mandato: abrirás tu mano a tu hermano, al necesitado y al pobre de tu tierra».

El propio Octavio Paz, un pensador para nada sospechoso de socialismo, advertía también en una entrevista que la fraternidad es la «gran ausente de nuestras sociedades capitalistas contemporáneas», de modo que nuestro deber -concluía- es «redescubrirla y ejercitarla».

Bobbio no es precisamente un pensador ingenuo, ni siquiera optimista, sino, todo lo contrario, alguien más bien propenso, según propia confesión, 
«a ver el lado oscuro de las cosas». Él conoce muy bien las dificultades que existen para combinar un proyecto de «socialismo liberalizado» con un «liberalismo socialmente responsable». Es más: en una conversación con Giancarlo Rosetti -a quien pertenecen las dos expresiones anteriores- Bobbio declaró que «hasta ahora nadie ha encontrado la manera de poner de acuerdo los derechos de la libertad con las exigencias de la justicia social». Por consiguiente, quizás tenga razón Perry Anderson, cuando comentando el liberalsocialismo de Bobbio, exclama «It is too soon», o sea, es demasiado pronto todavía para algo así, lo cual significaría -en palabras ahora del propio Bobbio- «que no tenemos aun ideas muy claras sobre el camino a recorrer».

Sin embargo, el liberalsocialismo de Bobbio y otros continúa siendo una dirección, y marcar la dirección en que queremos avanzar es siempre algo previo y más importante que la elección de los caminos que deberíamos tomar.

Para hallar esos caminos en nuestro continente, haría falta, como dice Carlos Fuentes, que algún día nuestra imaginación política, económica, e incluso moral, puedan igualar a nuestra imaginación verbal; o, como dice otro de nuestros escritores -Fernández Retamar-, haría falta poner nuestras ciencias sociales a la altura de nuestro arte y de nuestra poesía; o, como propone Mario Vargas Llosa, por mencionar a un escritor e intelectual que no estaría muy de acuerdo con los planteamientos de Bobbio, haría falta resignarnos alguna vez en América Latina a la idea de ser originales.

Por último, es prácticamente inevitable que una disertación acerca de la igualdad no contenga hoy en día alguna referencia a las ideas que Francis Fukuyama vierte en su ya conocidísimo libro «El fin de la historia y el último hombre», una obra que, por discutible que resulte la tesis central del autor -que también ha sido a veces harto mal comprendida y poco valorada- constituye bastante más de lo que comúnmente se llama «un libro de avión», esos que dejamos olvidados sobre la poltrona después de un largo viaje, sin molestarnos siquiera en devolverlo a nuestro equipaje de mano.

Por supuesto que la tesis de Fukuyama no dice relación con el fin de la historia entendido como una súbita interrupción de los humanos acontecimientos -que se siguen y continuarán sucediéndose, frenéticos, ante nuestra atónita y casi siempre sobrepasada capacidad de percepción-, ni, tampoco, con el término de la historia como estudio, reconstrucción conceptual y búsqueda de un probable sentido de los hechos del pasado. Fukuyama, por cierto, no ha pretendido congelar el presente, clausurar todo futuro devenir ni tampoco jubilarse o jubilar de paso a todos sus colegas historiadores.

No; la tesis de Fukuyama dice relación con el altísimo grado de consenso logrado en nuestra época respecto de la legitimidad de la democracia 
como forma de gobierno de la sociedad y de la mayor eficiencia de la llamada economía libre o de mercado como sistema más adecuado para alcanzar el crecimiento y la prosperidad material de los pueblos.

La propuesta de Fukuyama es que ese doble triunfo del liberalismo -en el plano político y en el campo económico- pone algo así como un «punto final a la evolución ideológica de la humanidad», desde el momento que ésta habría encontrado la «forma final de gobierno», con su ineludible correlato en el terreno económico, de manera que hoy, incluso allí donde no la había hasta hace poco o donde todavía ella no existe o trata de afirmarse con evidentes dificultades, la democracia liberal sería «la única aspiración política coherente que abarca las diferentes culturas y regiones del planeta».

Se trata, pues, del fin de la historia como fin de las ideologías, mejor aún, del fin de las luchas entre diferentes ideologías, al quedar una de éstas dueña de todo el campo, sin que ningún otro modelo alternativo -el último habría sido el comunismo hasta antes de su estrepitosa caída- se ofrezca o pueda ofrecer hoy plausiblemente y con posibilidades reales de ser compartido e implementado a una escala mundial relevante.

Dejando de lado los fundamentos de esta tesis y, sobre todo, su carácter altamente polémico, ¿qué tiene ella que ver con el problema de la igualdad, que es el que a nosotros preocupa en la presente intervención?

Fukuyama puede ser un pensador algo temerario, pero sabe dar razones y es capaz, asimismo, de darse cuenta de qué lado vendrán los tiros en contra de su propuesta. Vendrán, cree él, tanto de la izquierda como de la derecha, aunque confiesa que la crítica más poderosa, en su opinión, es la que proviene de ésta y no de aquélla. A nuestro modo de ver, sin embargo, el punto es otra vez debatible, pareciéndonos que lo que Fukuyama denomina crítica desde la izquierda es tal vez más consistente, simplemente por que parece tener mayor asidero en los hechos.

¿Y cuáles son esas dos críticas, una desde la izquierda y otra desde la derecha, que el autor que venimos citando identifica en relación con su propia tesis del fin de la historia en el sentido antes expuesto?

Fukuyama piensa que la democracia liberal y el régimen de economía libre proporcionarán en las distintas sociedades un mayor reconocimiento y bienestar a un mayor número de individuos, aunque este reconocimiento y bienestar, desde una perspectiva de izquierda, no será nunca estimado como completamente satisfactorio, desde el momento que el triunfante modelo se mostrará incapaz de corregir las profundas desigualdades económicas que el mismo sistema produce entre la gente. Así, como decía Adam Smith, el sistema permitirá que continúen habiendo «ricos que se vanaglorien de su riqueza, mientras los pobres continuarán avergonzándose de su pobreza y sintiéndose invisibles para los demás hombres». En consecuencia, esos pobres 
continuarán presionando por la búsqueda de alternativas a una democracia política simplemente acompañada de un capitalismo que en lo económico los hunde, o a lo menos los estabiliza, en una situación de evidente desigualdad material.

Tal es la crítica desde la izquierda que Fukuyama advierte en contra de su tesis.

¿Y a la de la derecha?

Fukuyama dice que el mayor bienestar y el igual reconocimiento dispensado por la democracia liberal favorecerá la complacencia y el conformismo, produciendo un rebaño de personas satisfechas, de «hombres sin pecho», como apuntó Nietzche, esto es, de individuos sin ideales y enteramente desmovilizados para conseguir mayores cuotas de reconocimiento individual que les permita percibirse a sí mismos, a la vez que iguales, superiores a los demás. Porque, como el mismo Fukuyama se pregunta, «¿no constituye el deseo de desigual reconocimiento la base de una vida vivible, no sólo en las sociedades aristocráticas del pasado, sino también en las democracias liberales del presente? ¿No depende en cierta medida su futura supervivencia del grado en que sus ciudadanos busquen que se les reconozca no sólo como iguales, sino como superiores a otros? ¿Y no puede el temor a convertirse en despreciables «últimos hombres» llevar a los hombres a afirmarse de maneras imprevistas y nuevas, incluso hasta el punto de convertirse de nuevo en bestiales «primeros hombres» consagrados a sangrientos combates de prestigio, ahora con armas modernas?».

Fukuyama es también un autor que sabe hacer preguntas y que valora la duda acerca de la pertinencia de su propia tesis, porque hacia el final de su libro, valiéndose de la hermosa y sugerente imagen de unas carretas que avanzan en caravana hacia la ciudad prometida, coincide en que no podemos saber con certeza si sus ocupantes, llegados a ésta, «después de echar una ojeada al nuevo paisaje no lo encontrarán a su gusto y posarán la mirada en otro viaje nuevo y más distante».

Bobbio, creo yo, forma parte de quienes piensan que ese viaje es no sólo posible, sino necesario. 